\title{
HEAVY ALCOHOL USE AND SUICIDAL BEHAVIOR AMONG PEOPLE WHO USE ILLICIT DRUGS: A COHORT STUDY
}

\author{
Mary Clare Kennedy ${ }^{1,2}$, Brandon D.L Marshall ${ }^{4}$, Kanna Hayashi ${ }^{1}$, Paul Nguyen ${ }^{1}$, Evan \\ Wood $^{1,3}$, and Thomas Kerr ${ }^{1,3}$ \\ ${ }^{1}$ British Columbia Centre for Excellence in HIV/AIDS, St. Paul's Hospital, 608-1081 Burrard \\ Street, Vancouver, BC, CANADA, V6Z 1 Y6 \\ ${ }^{2}$ School of Population and Public Health, University of British Columbia, 5804 Fairview Avenue, \\ Vancouver, BC, CANADA, V6T 1 Z3 \\ ${ }^{3}$ Department of Medicine, University of British Columbia, St. Paul's Hospital, 608-1081 Burrard \\ Street, Vancouver, BC, CANADA, V6Z 1 Y6 \\ ${ }^{4}$ Department of Epidemiology, Brown University School of Public Health, 121 South Main Street, \\ Providence, RI, USA, 02912
}

\section{Abstract}

\begin{abstract}
Background-People who use illicit drugs (PWUD) are known to experience high rates of suicidal behavior. While heavy alcohol use has been associated with suicide risk, its impact on the suicidal behavior of PWUD has not been well characterized. Therefore, we examined the relationship between heavy alcohol use and suicidal behavior among PWUD in Vancouver, Canada.
\end{abstract}

Methods-Data are derived from two prospective cohort studies of PWUD in Vancouver, Canada, from 2005 to 2013. Participants completed questionnaires that elicited information regarding sociodemographics, drug use patterns, and mental health problems, including suicidal behavior. We used recurrent event survival analyses to estimate the independent association between at-risk/heavy drinking (based on National Institute of Alcohol Abuse and Alcoholism [NIAAA] criteria) and risk of incident, self-reported suicide attempts.

() 2015 Published by Elsevier Ltd.

Send correspondence to: Thomas Kerr, Director, Urban Health Research Initiative, B.C. Centre for Excellence in HIV/AIDS, University of British Columbia, St. Paul's Hospital, 608-1081 Burrard Street, Vancouver, B.C., V6Z 1Y6, Canada, Tel: (604) 806-9116, Fax: (604) 806-9044, uhri-tk@cfenet.ubc.ca.

Publisher's Disclaimer: This is a PDF file of an unedited manuscript that has been accepted for publication. As a service to our customers we are providing this early version of the manuscript. The manuscript will undergo copyediting, typesetting, and review of the resulting proof before it is published in its final citable form. Please note that during the production process errors may be discovered which could affect the content, and all legal disclaimers that apply to the journal pertain.

Contributors:

The specific contributions of each author are as follows: MCK, TK, EW, and BM were responsible for study design; PN conducted the statistical analyses; MCK prepared the first draft of the manuscript; all authors revised the manuscript and approved the final version to be submitted.

Conflict of Interest:

The authors declare that they have no conflicts of interests. 
Results-Of 1,757 participants, 162 participants (9.2\%) reported 227 suicide attempts over the 8 -year study period, resulting in an incidence rate of 2.5 cases per 100 person-years. After adjusting for potential confounders, including intensive illicit drug use patterns, heavy alcohol use (adjusted hazard ratio $[\mathrm{AHR}]=1.97 ; 95 \%$ confidence interval $[\mathrm{CI}]=1.39,2.78$ ) was positively associated with an increased risk of suicidal behavior.

Conclusions-We observed a high burden of suicidal behavior among a community-recruited sample of PWUD. Heavy alcohol use predicted a higher risk of suicide attempt, independent of other drug use patterns. These findings demonstrate the need for evidence-based interventions to address suicide risk among PWUD, particularly those who are heavy consumers of alcohol.

\section{Keywords}

alcohol; suicide; illicit drug use; survival analysis; Canada

\section{INTRODUCTION}

People who use illicit drugs (PWUD) are known to commonly experience mental health problems, including suicidal ideation and behavior (Darke et al., 2010, Maloney et al., 2007, Marshall et al., 2013, Rossow and Lauritzen, 1999), with suicide being a leading cause of premature death among this population (Darke and Ross, 2002; Bohnert et al., 2010). A growing body of research has identified various correlates of suicidal behavior among PWUD, including substance use-related factors such as heavy illicit drug use patterns (Marshall et al., 2011), longer durations of drug use (Ilgen et al., 2007a; Landheim et al., 2006), and use of injection methamphetamine (Marshall et al., 2011) and injection cocaine (Darke and Kaye, 2004). However, few of these studies have considered heavy alcohol use as a potential explanatory variable. Although heavy alcohol use is a well-documented independent risk factor for fatal and non-fatal suicidal behavior among general populations (Borges et al., 2000, Borges and Loera, 2010, Kessler et al., 1999, Vijayakumar et al., 2011, Wilcox et al., 2004), it is not known if heavy alcohol use confers an independent risk of suicidal behavior among PWUD, in particular persons who report consistently intensive illicit drug use patterns. However, alcohol use has been associated with other adverse outcomes among PWUD, including non-fatal overdose (Dietze et al., 2005), HIV acquisition (Howe et al., 2011), poorer life satisfaction (Dietze et al., 2013), and violent victimization and perpetration (Dietze et al., 2013; Marshall et al., 2008). The present study was therefore conducted to determine if an independent association exists between heavy alcohol use patterns and repeated suicide attempts, measured prospectively in a community-recruited cohort of PWUD in Vancouver, Canada.

\section{METHODS}

\subsection{Study Sample}

The Vancouver Injection Drug Users Study (VIDUS) and the AIDS Care Cohort to evaluate Exposure to Survival Services (ACCESS) are two concurrent community-recruited prospective cohort studies of PWUD operating in Vancouver, Canada. Participants have been recruited through self-referral, snowball sampling, and street outreach since May,

Drug Alcohol Depend. Author manuscript; available in PMC 2016 June 01. 
1996. These cohorts have been described in detail previously (Strathdee et al., 1997; Tyndall et al., 2003). In brief, persons were eligible to enter the VIDUS study if they had injected illicit drugs at least once in the previous month at enrollment. Persons were eligible to enter the ACCESS study if they were HIV-infected and used illicit drugs other than or in addition to cannabinoids in the previous month. Individuals who seroconvert following recruitment are transferred from the VIDUS study into the ACCESS study. All eligible participants provided written informed consent. The study was approved by the University of British Columbia/Providence Health Care Research Ethics Board.

At baseline and semi-annually, all study participants in both cohorts complete a harmonized interviewer-administered questionnaire that elicits information on sociodemographics, drug use and other behavioral patterns, including suicidal behavior. In addition, participants also provide blood samples for HIV and hepatitis C testing, and HIV disease monitoring. At the conclusion of each visit, study participants receive a $\$ 20 \mathrm{CDN}$ honorarium. Detailed measures of alcohol use were added to the study instrument in December, 2005; therefore, we restricted our analyses to the 1757 individuals who were enrolled and completed at least 1 follow-up visit between December, 2005 and November, 2013.

\subsection{Measures}

The primary outcome for this analysis was response to the question, "Have you actually attempted suicide in the last 6 months?" Participants who responded affirmatively were counseled by on-site nurses and referred to additional services, if appropriate. The primary exposure of interest was at-risk/heavy alcohol use, which was defined according to the National Institute on Alcohol Abuse and Alcoholism (NIAAA) criteria for "heavy" or "atrisk" drinking: average of $>3$ alcoholic drinks per occasion or $>7$ drinks per week in the past six months for women, and an average of $>4$ alcoholic drinks per occasion or $>14$ drinks in total per week in the past six months for men (NIAAA, 2010). This measure is widely used in research in North America and was therefore employed in order to be consistent with the existing literature in this area.

To examine the extent to which heavy alcohol use contributes to suicidal behavior beyond other established risk factors, we assessed as potential confounders variables that are known to increase the risk of attempting suicide: age (per year older), sex (male vs. female), sexual orientation (heterosexual vs. lesbian, gay, bisexual, or transgender [LGBT]), Aboriginal ancestry (self-identified Aboriginal, First Nations, Inuit, or Métis ancestry vs. other), HIV status, determined by serological testing (positive vs. negative); and years injecting (per year increase since first time injecting). Other potential confounders examined included homelessness, incarceration, enrollment in drug/alcohol treatment, physical or sexual victimization, and sex work (all yes vs. no). Finally, we assessed as covariates high intensity use of non-injection crack, injectable heroin, injectable cocaine, and injectable crystal methamphetamine (all $\geq$ daily vs. <daily). Unless otherwise indicated, all variables refer to behaviors occurring in the 6-month period preceding the date of the interview.

Drug Alcohol Depend. Author manuscript; available in PMC 2016 June 01. 


\subsection{Analysis}

First, we calculated the incidence density of suicide attempts using person-time methods. Second, we used the Pearson's Chi-squared test for categorical variables and the MannWhitney test for continuous variables to compare baseline characteristics of those who reported attempting suicide during follow-up with those who did not.

Third, we used Kaplan-Meier methods (Kaplan and Meier, 1958) to determine the cumulative incidence of attempting suicide during follow-up among study participants, stratifying the sample by those who did and did not report heavy alcohol use at baseline. In this time to first event analyses, we right-censored all participants who reported suicidal behavior as of the date of their first suicide attempt reported during follow-up. Since the study questionnaire assesses suicidal behavior in the 6 months prior to the interview date and the precise date of suicide attempt is not known, we estimated the date of each attempted suicide event as the mid-point of the previous 6 months. We right-censored persons who never reported a suicide attempt during the follow-up period as of the date of their last visit. We used the log-rank test to compare the survival distributions of the 2 alcohol use categories (at-risk/heavy use vs. no at-risk/heavy use).

Because some participants reported more than 1 suicide attempt during the study period, we constructed a recurrent event survival model to examine the relationship between at-risk/ heavy alcohol use and the (repeated) outcome of interest. This model incorporated information on all suicide attempts recorded over the entire study period, and therefore improved precision of the effect estimate of interest. We used a proportional rates-means model described by Lin et al. (2000) to account for correlation among the length of individuals' repeated time at risk for a suicide attempt. In this model, we specified a counting process framework to define time to repeated events, such that individuals were considered to be at risk from time zero to the first event, from the first event to the second event, and so forth. As in the case of the Cox proportional hazards regression, the model assumed proportional means (Lin et al., 2000). We assessed this assumption for each variable of interest by visual inspection of the Schoenfeld residuals plots (Grambsch and Therneau, 1994) and by examining time-by-covariate interactions (Hess, 1994).

We first computed hazard ratios representing the bivariable associations between at-risk/ heavy drinking and potential confounders with repeated suicide attempts. We then applied an a priori defined approach that examined the independent effect of at-risk/heavy alcohol use by fitting a multivariable model that included all variables significantly associated with repeated suicide attempts at the $p<0.05$ level in bivariable analyses. Aboriginal ancestry was forced into the multivariable model to account for the well-established effect of this variable on the outcome of interest (Malchy et al., 1997; Cutliffe, 2005). Because of our interest in understanding the relationship between at-risk/heavy alcohol use and repeated suicide attempts independent of intensive illicit drug use patterns, daily injection crystal methamphetamine use and daily non-injection crack use were also forced into the model.

As a sub-analysis, we sought to determine whether a multivariable model fit using a backward elimination procedure significantly altered the results of the model fit using the $a$ priori defined statistical protocol. To do so, we included all variables in a backwards 
selection procedure based on the Akaike information criterion (AIC) and Type III $p$-values (Lima et al., 2008). Each variable with the highest $p$-value was removed sequentially, with the final model including the set of variables associated with the lowest AIC.

Finally, while the primary aim of the present study was to determine if at-risk/heavy alcohol use confers a risk of suicidal behavior independent of intensive illicit drug use patterns, we recognized that depression could confound this association (Conner and Duberstein, 2004). Therefore, we conducted a sensitivity analysis to determine whether including depression in our primary multivariable model would significantly alter the results. Depression was measured using the Center for Epidemiologic Studies Depression (CES-D) scale (Radloff, 1977), with a cutoff score of $\geq 22$ indicating depression. We conducted all statistical analyses with the SAS version 9.3 (SAS Institute Inc., Cary, NC), and all $p$-values are 2-sided.

\section{RESULTS}

The present study included the baseline and follow-up observations of 1757 PWUD, enrolled between December, 2005 and November, 2013. Participants were followed for a median follow-up time of 71.0 months (interquartile range $[\mathrm{IQR}]=39.9-86.5$ ), with similar follow-up times found for those who did and did not report heavy alcohol use at baseline ( $p=$ $0.63)$. The median age at baseline was 42 years ( $\mathrm{IQR}=35-48), 1163(66.2 \%)$ were male, and 592 (33.7\%) were of Aboriginal ancestry. During the 8 years of follow-up, 118 (6.7\%) participants reported 1 suicide attempt, $29(1.7 \%)$ reported 2 suicide attempts, $10(0.6 \%)$ reported 3 suicide attempts, $4(0.2 \%)$ reported 4 suicide attempts, and $1(0.1 \%)$ reported 5 suicide attempts, for a total of 227 events occurring among 162 participants. The resulting incidence density rate was 2.5 cases per 100 person-years $(95 \%$ confidence interval $[\mathrm{CI}]=$ 2.1,3.0). As shown in Table 1a, at baseline, persons who reported attempting suicide during follow-up were more likely than those who did not to: be younger (median age $=40$ vs. 42 ); be female (43.2\% vs. $32.9 \%$ ); self-identify as LGBT (20.4\% vs. $12.8 \%)$; report physical or sexual victimization ( $29.0 \%$ vs. $21.3 \%)$; be involved in sex work (21.6\% vs. $13.5 \%)$; and report at-risk/heavy alcohol use (27.8\% vs. $16.5 \%)$ (all $p<0.05)$.

As shown in Figure 1, 48 months after recruitment into the study the Kaplan-Meier cumulative incidence of the first self-reported attempted suicide was $14.6 \%$ among those who reported at-risk/heavy alcohol use, compared to $7.5 \%$ among those who did not report at-risk/heavy alcohol use (log-rank $p<0.001)$.

Table $1 \mathrm{~b}$ depicts the crude and adjusted hazard ratios of the recurrent events survival models between heavy alcohol use and other covariates with repeated suicide attempts. Visual inspection of the Schoenfeld residuals plots and examination of time-by-covariate interactions confirmed that each covariate met the proportional means assumption. In the multivariable model, after adjusting for various potential confounders, at-risk/heavy alcohol use (adjusted hazard ratio $[\mathrm{AHR}]=1.97 ; 95 \% \mathrm{CI}=1.39,2.78$ ), daily injection cocaine use $(\mathrm{AHR}=2.06 ; 95 \% \mathrm{CI}=1.38,3.08)$, and physical or sexual victimization $(\mathrm{AHR}=1.75 ; 95 \%$ $\mathrm{CI}=1.27,2.40$ ) were significantly and positively associated with an increased risk of suicidal behavior during the study period. The crude and adjusted hazard ratios for at-risk/

Drug Alcohol Depend. Author manuscript; available in PMC 2016 June 01. 
heavy alcohol use were similar, indicating little confounding by any of the covariates examined.

The multivariable model fit using a backward elimination procedure produced similar results: at-risk/heavy alcohol use, daily injection cocaine use, and physical or sexual victimization were all significantly and positively associated with risk of suicidal behavior over the study period, while male sex was significantly and negatively associated with the outcome (all $p<0.05$; data not shown).

Likewise, including depression as a covariate did not substantially alter the results of our primary multivariable model: at-risk/heavy alcohol use, daily injection cocaine use, physical or sexual victimization, and depression were all significantly and positively associated with an increased risk of suicidal behavior (all $p<0.05$; data not shown). We should note that approximately $14 \%(n=244)$ of participants had incomplete data for the depression variable and were excluded from this analysis. Compared to those with incomplete data, those included in this analysis were more likely to be male and older (both $p<0.05$ ) but were similar with respect to heavy alcohol use and suicidal behavior (both $p>0.05$ ).

\section{DISCUSSION}

In this prospective cohort study of more than 1700 PWUD in Vancouver, Canada, we observed a high rate of attempted suicide. In the Kaplan-Meier analyses, compared to those who did not report at-risk/heavy alcohol use, heavy alcohol users were almost twice as likely to report attempting suicide within 4 years of enrolling in the study. There was an increasing disparity over time in the cumulative incidence of first self-reported attempted suicide between these two groups, which may be because high-risk participants were more likely to attempt suicide earlier in the follow-up period.

In the adjusted recurrent event analyses, at-risk/heavy alcohol use, daily injection cocaine use, and victimization were associated with an increased hazard of suicide attempt. These findings are consistent with previous studies identifying intensive injection cocaine use (Darke and Kaye, 2004), and violent victimization (Darke et al., 2010; Lloyd et al., 2007) as risk factors for suicidal behavior among PWUD. Our findings are also in agreement with a large body of research documenting an association between heavy alcohol use and suicidal behavior among general populations (Borges et al., 2000, Borges and Loera, 2010, Kessler et al., 1999, Vijayakumar et al., 2011, Wilcox et al., 2004) and other, albeit few, studies identifying associations between alcohol use and adverse health and social outcomes among PWUD (Dietze et al., 2005, 2013, Howe et al., 2011, Marshall et al., 2008). However, to our knowledge, ours is the first study to prospectively identify a relationship between heavy drinking patterns and suicidal behavior among a community-recruited cohort of PWUD, after extensive adjustment for intensive illicit drug use patterns.

These findings suggest that interventions to reduce heavy alcohol consumption among PWUD may contribute to reductions in suicidal behavior. This assertion is supported by recent observational research, which suggests that addiction treatment may reduce suicidal behavior among people with substance use disorders (Ilgen et al., 2007a, 2007b). Further,

Drug Alcohol Depend. Author manuscript; available in PMC 2016 June 01. 
programs that serve PWUD should screen for alcohol use and offer suicide prevention and other mental health interventions to PWUD who are also heavy alcohol users.

A number of limitations common to observational cohort studies apply to the current analysis. The VIDUS and ACCESS cohorts are community-recruited, non-randomized samples of people who inject drugs and HIV-infected PWUD other than or in addition to cannabinoids, respectively. Therefore, our findings may not be generalizable to drug-using populations in local or other settings. Additionally, this study relied on self-reported information. While all questions regarding suicidal behavior were asked by trained nurses who have extensive experience working with the study population, suicide attempts may have been underreported due to social desirability bias. Finally, the relationship between heavy alcohol use and suicidal behavior may be influenced by variables, including symptoms and treatment of psychiatric conditions and other potential confounders, not examined as part of the VIDUS or ACCESS studies.

In conclusion, this study reports a previously unidentified association between heavy drinking patterns and repeated suicide attempts among PWUD. This association merits further investigation. In particular, future studies should examine the association between trajectories of alcohol use and suicidal behavior among PWUD in order to elucidate the effect of heterogeneities in patterns of use over time. Additionally, future research should consider mental health treatment and past suicidal behavior as covariates given that mental health treatment may reduce the risk of suicidal behavior (Mann et al., 2005) and that past suicidal behavior is one of the most robust risk factors for future suicidal behavior (Borges et al., 2006). Nonetheless, the findings of the present study suggest that interventions to reduce heavy alcohol use among PWUD may mitigate suicidal behavior among this marginalized population, and should therefore be an integral part of suicide prevention efforts.

\section{Acknowledgments}

Role of Funding Source:

This funding source had no further role in study design; in the collection, analysis and interpretation of data; in the writing of the report; or in the decision to submit the paper for publication.

The authors thank the study participants for their contribution to the research, as well as current and past researchers and staff. The study was supported by the US National Institutes of Health (R01 DA011591 R01 DA021525). This research was undertaken, in part, thanks to funding from the Canada Research Chairs program through a Tier 1 Canada Research Chair in Inner city Medicine which supports Dr. Evan Wood. Dr. Brandon Marshall is supported by a Richard B. Salomon Faculty Research Award from Brown University. Dr. Kanna Hayashi is supported by the Canadian Institutes of Health Research.

\section{REFERENCES}

Bohnert ASB, Roeder K, Ilgen MA. Unintentional overdose and suicide among substance users: a review of overlap and risk factors. Drug Alcohol Depend. 2010; 110:183-192. [PubMed: 20430536]

Borges G, Angst J, Nock MK, Ruscio AM, Walters EE, Kessler RC. A risk index for 12-month suicide attempts in the National Comorbidity Survey Replication (NCS-R). Psychol. Med. 2006; 36:17471757. [PubMed: 16938149] 
Borges G, Loera CR. Alcohol and drug use in suicidal behavior. Curr. Opin. Psychiatry. 2010; 23:195204. [PubMed: 20308904]

Borges G, Walters EE, Kessler RC. Associations of substance use, abuse, and dependence with subsequent suicidal behavior. Am. J. Epidemiol. 2000; 151:781-789. [PubMed: 10965975]

Conner KR, Duberstein PR. Predisposing and precipitating factors for suicide among alcoholics: empirical review and conceptual integration. Alcohol. Clin. Exp. Res. 2004; 28:6S-17S. [PubMed: 15166632]

Cutcliffe JR. Toward an understanding of suicide in First-Nation Canadians. Crisis. 2005; 26:141-145. [PubMed: 16276757]

Darke S, Kaye DS. Attempted suicide among injecting and noninjecting cocaine users in Sydney, Australia. J. Urban Health. 2004; 81:505-515. [PubMed: 15273272]

Darke S, Ross J. Suicide among heroin users: rates, risk factors and methods. Addiction. 2002; 97:1383-1394. [PubMed: 12410779]

Darke S, Torok M, Kaye S, Ross J. Attempted suicide, self-harm, and violent victimization among regular illicit drug users. Suicide Life Threat. Behav. 2010; 40:587-596. [PubMed: 21198327]

Dietze P, Jenkinson R, Aitken C, Stoové M, Jolley D, Hickman M, Kerr T. The relationship between alcohol use and injecting drug use: impacts on health, crime and wellbeing. Drug Alcohol Depend. 2013; 128:111-115. [PubMed: 22989499]

Dietze P, Jolley D, Fry C, Bammer G. Transient changes in behaviour lead to heroin overdose: results from a case-crossover study of non-fatal overdose. Addiction. 2005; 100:636-642. [PubMed: 15847621]

Grambsch PM, Therneau TM. Proportional hazards tests and diagnostics based on weighted residuals. Biometrika. 1994; 81:515-526.

Hess KR. Assessing time-by-covariate interactions in proportional hazards regression models using cubic spline functions. Statist. Med. 1994; 13:1045-1062.

Howe CJ, Cole SR, Ostrow DG, Mehta SH, Kirk GD. A prospective study of alcohol consumption and HIV acquisition among injection drug users. AIDS. 2011; 25:221-228. [PubMed: 21099668]

Ilgen MA, Harris AHS, Moos RH, Tiet QQ. Predictors of a suicide attempt one year after entry into substance use disorder treatment. Alcohol. Clin. Exp. Res. 2007a; 31:635-642. [PubMed: 17374043]

Ilgen MA, Jain A, Lucas E, Moos RH. Substance use-disorder treatment and a decline in attempted suicide during and after treatment. J. Stud. Alcohol Drugs. 2007b; 68:503-509. [PubMed: 17568953]

Kaplan EL, Meier P. Nonparametric estimation from incomplete observations. J. Am. Statist. Assoc. $1958 ; 53: 457-481$.

Kessler RC, Borges G, Walters EE. Prevalence of and risk factors for lifetime suicide attempts in the national comorbidity survey. Arch. Gen. Psychiatry. 1999; 56:617-626. [PubMed: 10401507]

Krupitsky E, Nunes EV, Ling W, Illeperuma A, Gastfriend DR, Silverman BL. Injectable extendedrelease naltrexone for opioid dependence: a double-blind, placebo-controlled, multicentre randomised trial. Lancet. 2011; 377:1506-1513. [PubMed: 21529928]

Landheim AS, Bakken K, Vaglum P. What characterizes substance abusers who commit suicide attempts? Factors related to Axis I disorders and patterns of substance use disorders. A study of treatment-seeking substance abusers in Norway. Eur. Addict. Res. 2006; 12:102-108. [PubMed: 16543746]

Lima VD, Harrigan R, Murray M, Moore DM, Wood E, Hogg RS, Montaner JS. Differential impact of adherence on long-term treatment response among naive HIV-infected individuals. AIDS. 2008; 22:2371-2380. [PubMed: 18981777]

Lin DY, Wei LJ, Yang I, Ying Z. Semiparametric regression for the mean and rate functions of recurrent events. J. R. Stat. Soc. Series B Stat. Methodol. 2000; 62:711-730.

Lloyd JJ, Ricketts EP, Havens JR, Cornelius LJ, Bishai D, Huettner S, Latkin C, Strathdee SA. The relationship between lifetime abuse and suicidal ideation in a sample of injection drug users. J. Psychoactive Drugs. 2007; 39:159-166. [PubMed: 17703710]

Malchy B, Enns MW, Young TK, Cox BJ. Suicide among Manitoba's aboriginal people, 1988 to 1994. Can. Med. Assoc. J. 1997; 156:1133-1138. [PubMed: 9141983] 
Maloney E, Degenhardt L, Darke S, Mattick RP, Nelson E. Suicidal behaviour and associated risk factors among opioid-dependent individuals: a case-control study. Addiction. 2007; 102:19331941. [PubMed: 17784898]

Mann JJ, Apter A, Bertolote J, Beautrais A, Currier D, Haas A, Hegerl U, Lonnqvist J, Malone K, Marusic A, Mehlum L, Patton G, Phillips M, Rutz W, Rihmer Z, Schmidtke A, Shaffer D, Silverman M, Takahashi Y, Varnik A, Wasserman D, Yip P, Hendin H. Suicide prevention strategies: a systematic review. JAMA. 2005; 294:2064-2074. [PubMed: 16249421]

Marshall BDL, Fairbairn N, Li K, Wood E, Kerr T. Physical violence among a prospective cohort of injection drug users: a gender-focused approach. Drug Alcohol Depend. 2008; 97:237-246. [PubMed: 18487025]

Marshall BDL, Galea S, Wood E, Kerr T. Injection methamphetamine use is associated with an increased risk of attempted suicide: a prospective cohort study. Drug Alcohol Depend. 2011; 119:134-137. [PubMed: 21676557]

Marshall BDL, Galea S, Wood E, Kerr T. Longitudinal associations between types of childhood trauma and suicidal behavior among substance users: a cohort study. Am. J. Public Health. 2013; 103:e69-e75. [PubMed: 23865651]

National Institute on Alcohol Abuse and Alcoholism. [Accessed on 9/30/2014] Rethinking drinking: Alcohol and Your Health. NIH Publication No. 13-3770. 2010. from http://pubs.niaaa.nih.gov/ publications/RethinkingDrinking/Rethinking_Drinking.pdf

Radloff LS. The CES-D Scale: a self-report depression scale for research in the general population. Appl. Psychol. Meas. 1977; 1:385-401.

Rossow I, Lauritzen G. Balancing on the edge of death: suicide attempts and life-threatening overdoses among drug addicts. Addiction. 1999; 94:209-219. [PubMed: 10396789]

Strathdee SA, Patrick DM, Currie SL, Cornelisse PG, Rekart ML, Montaner JS, Schechter MT, O'Shaughnessy MV. Needle exchange is not enough: lessons from the Vancouver injecting drug use study. AIDS. 1997; 11:F59-F65. [PubMed: 9223727]

Tyndall MW, Currie S, Spittal P, Li K, Wood E, O’Shaughnessy MV, Schechter MT. Intensive injection cocaine use as the primary risk factor in the Vancouver HIV-1 epidemic. AIDS. 2003; 17:887-893. [PubMed: 12660536]

Vijayakumar L, Kumar MS, Vijayakumar V. Substance use and suicide. Curr. Opin. Psychiatry. 2011; 24:197-202. [PubMed: 21430536]

Wilcox HC, Conner KR, Caine ED. Association of alcohol and drug use disorders and completed suicide: an empirical review of cohort studies. Drug Alcohol Depend. 2004; 76(Suppl.):S11-S19. [PubMed: 15555812] 


\section{HIGHLIGHTS}

- We investigated the association between at-risk/heavy alcohol use and suicidal behavior among people who use drugs over eight years.

- Data from two prospective cohort studies of people who use drugs were examined using recurrent event survival analyses.

- At-risk/heavy alcohol use patterns predicted a higher risk of repeated suicide attempts, independent of drug use patterns and other relevant factors. 


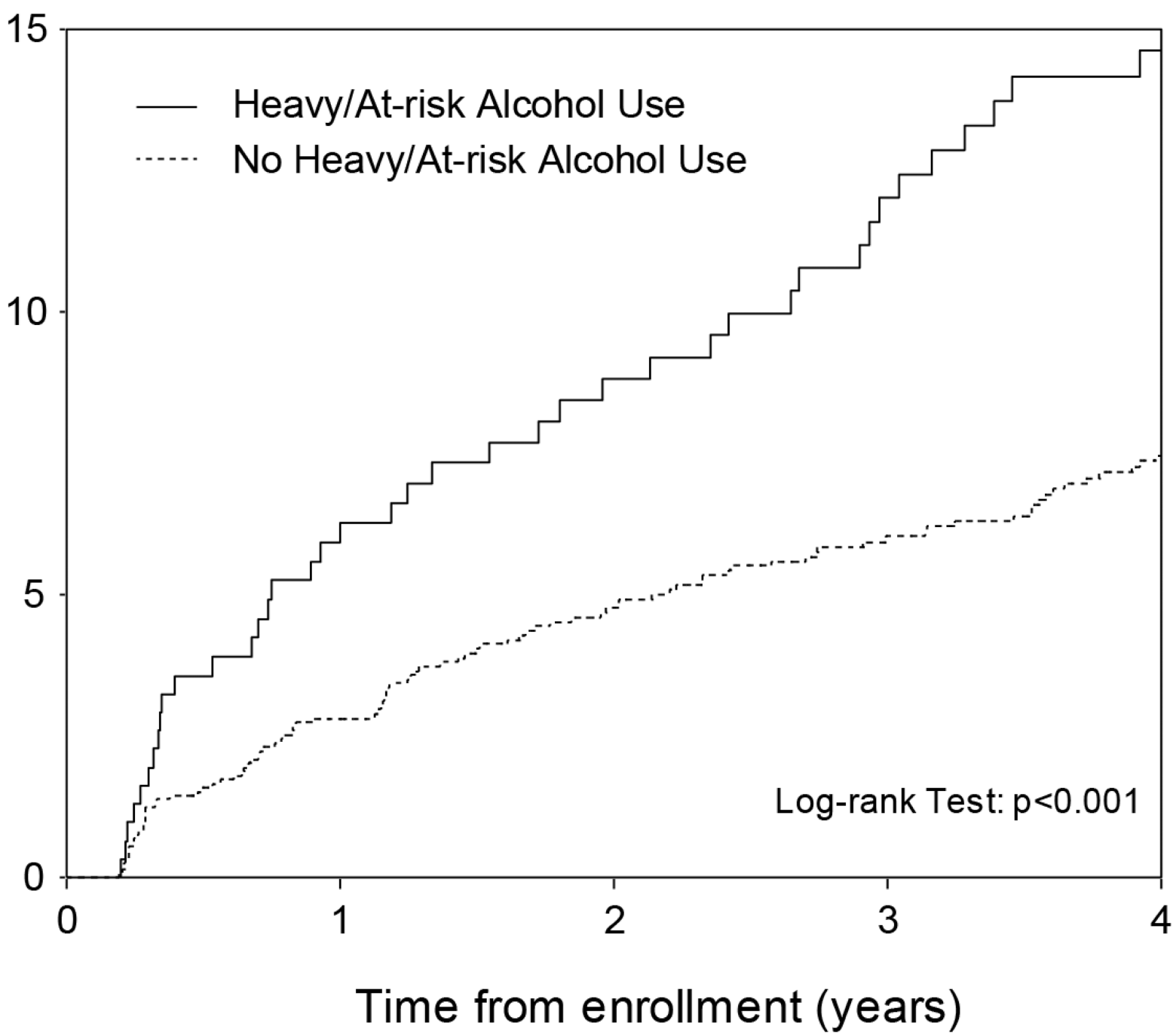

Figure 1.

Cumulative incidence of first self-reported suicide attempt, stratified by severity of alcohol use among illicit drug users in Vancouver, Canada (2005-2013). 


\section{TABLE 1}

\begin{tabular}{|c|c|c|c|c|}
\hline \multirow[b]{2}{*}{ Characteristic } & \multirow{2}{*}{$\begin{array}{l}\text { Total }(\%) \\
(n=1757)\end{array}$} & \multicolumn{2}{|c|}{ Attempted Suicide ${ }^{f}$} & \multirow[b]{2}{*}{$p$-value } \\
\hline & & $\begin{array}{c}\text { Yes (\%) } \\
(n=162)\end{array}$ & $\begin{array}{c}\text { No (\%) } \\
(n=1595)\end{array}$ & \\
\hline \multicolumn{5}{|l|}{ Age } \\
\hline Median [IQR] & $42[35-48]$ & $40[33-46]$ & $42[36-48]$ & 0.007 \\
\hline \multicolumn{5}{|l|}{ Sex } \\
\hline Male & $1163(66.2)$ & $92(56.8)$ & $1071(67.1)$ & 0.008 \\
\hline Female & $594(33.8)$ & $70(43.2)$ & $524(32.9)$ & \\
\hline \multicolumn{5}{|c|}{ Sexual orientation } \\
\hline Heterosexual & $1497(85.2)$ & $127(78.4)$ & $1370(85.9)$ & 0.007 \\
\hline LGBT & $237(13.5)$ & $33(20.4)$ & $204(12.8)$ & \\
\hline \multicolumn{5}{|c|}{ Aboriginal ancestry } \\
\hline Yes & $592(33.7)$ & $64(39.5)$ & $528(33.1)$ & 0.100 \\
\hline No & $1165(66.3)$ & $98(60.5)$ & $1067(66.9)$ & \\
\hline \multicolumn{5}{|l|}{ Years injecting } \\
\hline Median [IQR] & $19[11-28]$ & 18 [12-26] & $19[11-28]$ & 0.839 \\
\hline \multicolumn{5}{|l|}{ HIV Positive } \\
\hline Yes & 715 (40.7) & $64(39.5)$ & $651(40.8)$ & 0.747 \\
\hline No & $1042(59.3)$ & $98(60.5)$ & $944(59.2)$ & \\
\hline \multicolumn{5}{|l|}{ Homeless* } \\
\hline Yes & $585(33.3)$ & $59(36.4)$ & $526(33.0)$ & 0.327 \\
\hline No & $1167(66.4)$ & $101(62.3)$ & $1066(66.8)$ & \\
\hline \multicolumn{5}{|c|}{ Heavy alcohol use $* \dagger$} \\
\hline Yes & $308(17.5)$ & $45(27.8)$ & $263(16.5)$ & $<0.001$ \\
\hline No & $1449(82.5)$ & $117(72.2)$ & $1332(83.5)$ & \\
\hline \multicolumn{5}{|c|}{ Non-injection crack use ${ }^{*}$} \\
\hline$\gg$ Daily & $682(38.8)$ & $64(39.5)$ & $618(38.7)$ & 0.850 \\
\hline$<$ Daily & $1075(61.2)$ & $98(60.5)$ & $977(61.3)$ & \\
\hline \multicolumn{5}{|c|}{ Injection heroin use ${ }^{*}$} \\
\hline$\searrow$ Daily & $430(24.5)$ & $46(28.4)$ & $384(24.1)$ & 0.214 \\
\hline$<$ Daily & $1321(75.2)$ & $115(71.0)$ & $1206(75.6)$ & \\
\hline \multicolumn{5}{|c|}{ Injection cocaine use ${ }^{*}$} \\
\hline$\gg$ Daily & $166(9.4)$ & $14(8.6)$ & $152(9.5)$ & 0.739 \\
\hline$<$ Daily & $1584(90.2)$ & $146(90.1)$ & $1438(90.2)$ & \\
\hline \multicolumn{5}{|c|}{ Injection crystal methamphetamine use ${ }^{*}$} \\
\hline$\gg$ Daily & $59(3.4)$ & $8(4.9)$ & $51(3.2)$ & 0.239 \\
\hline$<$ Daily & $1690(96.2)$ & $153(94.4)$ & $1537(96.4)$ & \\
\hline
\end{tabular}

Experience violence $^{*}$ 


\begin{tabular}{|c|c|c|c|c|}
\hline \multicolumn{5}{|c|}{$\begin{array}{l}\text { a. Sociodemographic, behavioral and clinical baseline characteristics of illicit drug users who did and did not attempt suicide }{ }^{f} \text { in } \\
\text { Vancouver, Canada (2005-2013) }\end{array}$} \\
\hline \multirow[b]{2}{*}{ Characteristic } & \multirow{2}{*}{$\begin{array}{l}\text { Total }(\%) \\
(n=1757)\end{array}$} & \multicolumn{2}{|c|}{ Attempted Suicide ${ }^{£}$} & \multirow[b]{2}{*}{$p$-value } \\
\hline & & $\begin{array}{c}\text { Yes }(\%) \\
(n=162)\end{array}$ & $\begin{array}{l}\text { No }(\%) \\
(n=1595)\end{array}$ & \\
\hline Yes & $387(22.0)$ & $47(29.0)$ & $340(21.3)$ & 0.027 \\
\hline No & $1339(76.2)$ & $113(69.8)$ & $1226(76.9)$ & \\
\hline \multicolumn{5}{|c|}{ Drug or alcohol treatment ${ }^{*}$} \\
\hline Yes & $871(49.6)$ & $85(52.5)$ & $786(49.3)$ & 0.433 \\
\hline No & $865(49.2)$ & $75(46.3)$ & $790(49.5)$ & \\
\hline \multicolumn{5}{|c|}{ Sex work involvement ${ }^{*}$} \\
\hline Yes & $250(14.2)$ & $35(21.6)$ & $215(13.5)$ & 0.006 \\
\hline No & $1483(84.4)$ & $126(77.8)$ & $1357(85.1)$ & \\
\hline \multicolumn{5}{|l|}{ Incarceration * } \\
\hline Yes & $294(16.7)$ & $26(16.0)$ & $268(16.8)$ & 0.816 \\
\hline No & $1445(82.2)$ & $134(82.7)$ & $1311(82.2)$ & \\
\hline
\end{tabular}

b. Unadjusted and adjusted hazard ratios for attempting suicide among illicit drug users in Vancouver, Canada (2005-2013)

\begin{tabular}{|c|c|c|c|c|}
\hline \multirow[b]{2}{*}{ Characteristic } & \multicolumn{2}{|c|}{ Unadjusted } & \multicolumn{2}{|c|}{ Adjusted } \\
\hline & $\begin{array}{l}\text { Hazard Ratio } \\
\quad(95 \% \text { CI })\end{array}$ & $p$ - value & $\begin{array}{l}\text { Hazard Ratio } \\
\quad(95 \% \text { CI })\end{array}$ & $p$-value \\
\hline \multicolumn{5}{|l|}{ Age } \\
\hline (per year older) & $0.98(0.96-0.99)$ & 0.004 & $0.99(0.97-1.00)$ & 0.133 \\
\hline \multicolumn{5}{|l|}{ Sex } \\
\hline (male vs. female) & $0.58(0.41-0.82)$ & 0.002 & $0.68(0.46-1.01)$ & 0.054 \\
\hline \multicolumn{5}{|l|}{ Sexual orientation } \\
\hline (heterosexual vs. LGBT) & $0.58(0.38-0.88)$ & 0.010 & $0.71(0.46-1.10)$ & 0.127 \\
\hline \multicolumn{5}{|l|}{ Aboriginal ancestry } \\
\hline (yes vs. no) & $1.38(0.97-1.96)$ & 0.072 & $1.13(0.77-1.66)$ & 0.531 \\
\hline \multicolumn{5}{|l|}{ Length of time injecting } \\
\hline (per year increase) & $1.00(0.98-1.01)$ & 0.873 & & \\
\hline \multicolumn{5}{|l|}{ HIV positive } \\
\hline (yes vs. no) & $1.10(0.79-1.55)$ & 0.568 & & \\
\hline \multicolumn{5}{|l|}{ Homeless * } \\
\hline (yes vs. no) & $1.38(1.00-1.91)$ & 0.050 & & \\
\hline \multicolumn{5}{|l|}{ Heavy alcohol use ${ }^{* \dagger}$} \\
\hline (yes vs. no) & $2.13(1.53-2.97)$ & $<0.001$ & $1.97(1.39-2.78)$ & $<0.001$ \\
\hline \multicolumn{5}{|c|}{ Daily non-injection crack use ${ }^{*}$} \\
\hline (yes vs. no) & $1.18(0.86-1.61)$ & 0.317 & $0.90(0.65-1.24)$ & 0.509 \\
\hline \multicolumn{5}{|l|}{ Daily injection heroin use ${ }^{*}$} \\
\hline (yes vs. no) & $1.47(1.06-2.02)$ & 0.019 & $1.25(0.90-1.75)$ & 0.189 \\
\hline \multicolumn{5}{|c|}{ Daily injection cocaine use ${ }^{*}$} \\
\hline (yes vs. no) & $2.13(1.43-3.18)$ & $<0.001$ & $2.06(1.38-3.08)$ & $<0.001$ \\
\hline
\end{tabular}




\begin{tabular}{|c|c|c|c|c|}
\hline \multirow[b]{2}{*}{ Characteristic } & \multicolumn{2}{|c|}{ Unadjusted } & \multicolumn{2}{|c|}{ Adjusted } \\
\hline & $\begin{array}{l}\text { Hazard Ratio } \\
\quad(95 \% \text { CI) }\end{array}$ & $p$ - value & $\begin{array}{l}\text { Hazard Ratio } \\
\quad(95 \% \text { CI })\end{array}$ & $p$-value \\
\hline \multicolumn{5}{|c|}{ Daily injection crystal methamphetamine use ${ }^{*}$} \\
\hline (yes vs. no) & $1.71(0.74-3.94)$ & 0.207 & $1.48(0.63-3.47)$ & 0.367 \\
\hline \multicolumn{5}{|c|}{ Experience violence ${ }^{*}$} \\
\hline (yes vs. no) & $1.87(1.38-2.54)$ & $<0.001$ & $1.75(1.27-2.40)$ & 0.001 \\
\hline \multicolumn{5}{|c|}{ Drug or alcohol treatment ${ }^{*}$} \\
\hline (yes vs. no) & $1.09(0.80-1.50)$ & 0.583 & & \\
\hline \multicolumn{5}{|c|}{ Sex work involvement ${ }^{*}$} \\
\hline (yes vs. no) & $1.68(1.11-2.52)$ & 0.014 & $1.03(0.64-1.64)$ & 0.907 \\
\hline \multicolumn{5}{|l|}{ Incarceration $*$} \\
\hline (yes vs. no) & $1.17(0.75-1.81)$ & 0.494 & & \\
\hline
\end{tabular}

Note: IQR = interquartile range; LGBT = lesbian, gay, bisexual, or transgender. Column percentages may not necessarily sum to $100 \%$ due to missing data or rounding error.

${ }^{£}$ Suicide attempt at some point during follow-up

*

Refers to activities in the past 6 months

t

${ }^{\dagger}$ Average of $>3$ alcoholic drinks on at least 1 day/week or $>7$ drinks in total/week (women), or $>4$ alcoholic drinks on at least 1 day/week or $>14$ drinks in total/week (men)

Note: $\mathrm{CI}=$ confidence interval.

Refers to activities in the past 6 months

${ }^{\dagger}$ Average of $>3$ alcoholic drinks on at least 1 day/week or $>7$ drinks in total/week (women), or $>4$ alcoholic drinks on at least 1 day/week or $>14$ drinks in total/week (men)

${ }^{£}$ Adjusted for age, sex, sexual orientation, Aboriginal ancestry, heavy alcohol use, daily noninjection crack use, daily heroin use, daily injection cocaine use, daily injection crystal methamphetamine use, physical or sexual victimization, and sex work involvement. 